\title{
Forest Management: Forest Fragmentation and Biodiversity Corridor Function of Riparian Forest in Lesser Antilles
}

\author{
L. Rolle \\ Faculty of Physics and Biology of Organisms and Ecosystems, University of the French West Indies, Guadeloupe
}

Copyright@2017 by authors, all rights reserved. Authors agree that this article remains permanently open access under the terms of the Creative Commons Attribution License 4.0 International License

\begin{abstract}
This case study is a part of a thesis we lead a botanical and ecological synthesis of Lesser-Antilles riparian forests by studying the forest connectivity in riparian area. The study employed geographic information system processing methods for assessing the integrity of riparian forest and the importance of this corridor function on the rainforest. The corridor function analysis is based on the structural fragmentation and the potential connectivity of the watershed patch forest. The principle of potential connectivity is constructed on the probability of a direct dispersion of floral and animal species between forest patch which is life habitat. This method allowed connectivity indices based on distance calculation between forest patches. The results order habitat patches by their significant weight in the connectivity graph. The question arises as to whether the riparian forest patch is a key habitat to maintain the connectivity quality of the watershed. Do they play their biological function of the corridor in the Lesser Antilles of Guadeloupe and Martinique?
\end{abstract}

Keywords Forest Fragmentation, Riparian Forest, Lesser Antilles, Corridor Function, GIS

\section{Introduction}

\subsection{The Environmental Issues of the Habitat Connectivity}

The connectivity indices revealed the forest landscape integrity. The state of integrity is a forest ecosystem split or not in patches which keep the habitat and the biodiversity flux safe. Despite the human development and the diversity of land use which restricts the forest area.

The valuation of the forest fragmentation allows us to draw ecological wellness the forest resource. A connected forest area supports the genetic flow of animal and vegetal species to reduce the landscape vulnerability because the forest wellness conserves the ecosystem functions which sustain the biodiversity. [1]

In Lesser Antilles, the forest ecosystem is treated by the urban sprawl. The national conservation protocols named "Trame verte et bleue" 1 manage the protection of the forest and aquatic biological corridor; having as a goal to restore the natural and semi-natural to maintain the ecological functions. [2]

The ecological functions help to maintain the ecosystem integrity and the human society well-being. Also, named ecological services, the ecosystem functions are all the physical and chemical effects of an individual or a population of the same species on their biological (other species) and physical (mesological terms) environment. [3]

The ability of human societies to identify and spatialize this function ensures the ecological wellness of our territories provided of our conservation strategies.

Ones of the strategy largely recommended is the conservation or the creation of corridor areas. This is a thin habitat area which has the function of a link, a way for the species between large habitat area (part of a landscape favor of maintaining biological diversity richness). [4]

In this context, the riparian area appears to be particularly important because this type of corridor develop in interface area between humid and forest ecosystems.

Functional analysis of riparian forests can register at two levels of scale in biodiversity. It is possible to realize the scale of organism quantitative measures on chemical, biochemical. With the help of remote sensing technologies, functional analysis is done at the landscape scale. Ecosystem functions are observed in the structure, patterns of landscapes. If one focuses on the study of the corridor function of the biodiversity of riparian forests; we can work on the structure, fragmented or not of the environment. This geometric analysis called wicks systematic reality of

1 Greenway and blue frame 
ecosystems and does not make the link with agencies and the biological reality of the territories. To study the ecological corridor reality or conversely fragmentation requires knowledge of plant and animal species; their capacity and type of mobility as well as the permeability of these environments. This is to formalize the distribution of environmental criteria that promote or constrain the distribution of species within the study area. Thus, landscape portions that promote species circulation will be identified as having a corridor function.

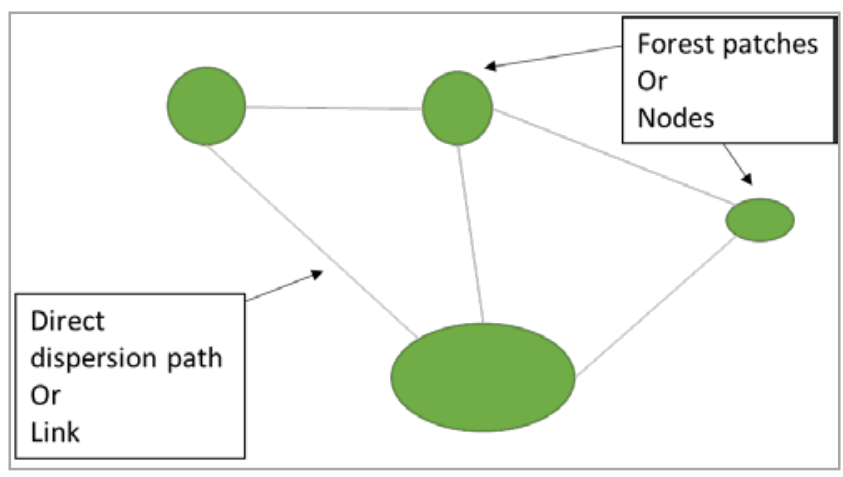

Figure 1. Graph Theory and Forest Connectivity

The protection of this biodiversity's reservoir can't be done without the ecological assessment of the watershed and the evaluation of the significance of riparian forest in the safeguard of biodiversity. In this study, we employed geographic information systems processing methods for assessing the integrity of riparian forest and the importance of this corridor function on the rainforest. The question we pose it's if the riparian forest patch is a key habitat to maintain the connectivity quality of the watershed. Do they play their biological function of the corridor in the Lesser Antilles of Guadeloupe and Martinique?

With the structural fragmentation and the potential connectivity index we test the corridor function of the watershed patch forest. The principle of potential connectivity is constructed on the probability of a direct dispersion of floral and animal species between forest patch which is life habitat. This has the advantage to assess the landscape viability without carry a large investigation of species mobility.

\section{Methods}

\subsection{The Connectivity Indices}

The fragmentation indices compute the geometrical organization of the forest areas/patches in a territory.

The structural fragmentation determines in a binary way the absence and the presence of a connection between two forest patches. This structural index estimates if the distance between two patches establish a frontier for the flow of species.

The potential fragmentation helps to calculate the probability for each forest patch to allow a direct dispersion between two patches in strength, frequency and feasibility in the hypothesis of a species migration.

On thirteen indexes commonly used, the IIC and the PC index are more efficient for detecting the key patches to maintain the connectivity network. [5]

For the study, we work with the IIC (integral index of connectivity) fragmentation indices develop for the Conefor sensinode 2.6 software.

"This concept consists of considering a habitat patch itself as a space where connectivity occurs, integrating the connected resources existing within the patches (intrapatch connectivity) with the resources made available by (reachable through) the connections with other habitat patches in the landscape (interpatch connectivity)." [6]

We work with the IIC index because it's more efficient to distinguish a general species movement.

The integral index of connectivity indicates the number of the shortest path between a pair of nodes habitat; weighted on the part of the patch in the landscape area.

The result orders the patches by their significant weight in the connectivity graph.

Intra: The possible internal flux if the patch was totally isolated (the part of the patch area in the total area landscape)

Flux: The amount of dispersion from a random origin or destination node of the dispersal flux of all the patches in the landscape

Connector: The contribution of the patch in the connectivity between two other habitat patches (as a corridor)

The total index is the sum of all these fractions.

The literature recommends using the IIC "connector" fraction to clearly identify the node importance to maintain the quality of the graph. The algorithms remove one by one all the patches and test their importance to maintain the connectivity. In the case study of riparian forest, this fraction helps to identify which forest node play a corridor function in the watershed area.

The integral index of connectivity returns a binary result between 0 and 1 where 0 is a total absence of connectivity therefore they no forest and 1 a total connectivity therefore a full forest landscape. [7]

$$
I I C=\frac{\sum_{i=1}^{n} \sum_{j=1}^{n} \frac{a_{i^{\prime}} a_{j}}{1+\mathrm{nl}_{i j}}}{A_{\mathrm{L}}^{2}}
$$

$a i=$ patch area; $n l i j=$ number of links in the shortest path distance; $i$ and $j=$ forest patches

\subsection{The Case Study of the Lesser Antilles Watershed}

We study the forest continuity in watershed area. Especially on riparian forest identify as natural corridor. They are a lack of studies on habitat fragmentation and on the role play by riparian forest for maintaining biodiversity on French Lesser Antilles. 


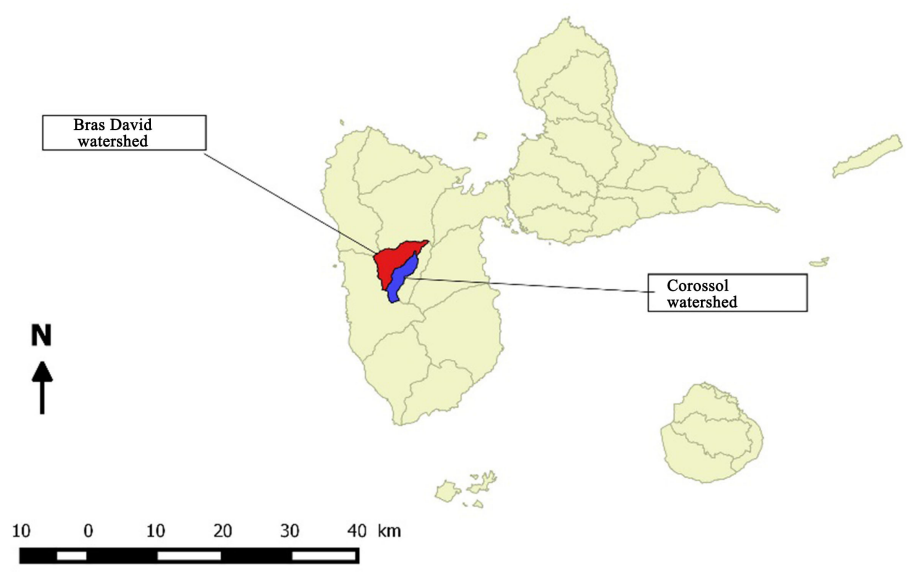

Figure2. Guadeloupe Archipelago and the watershed of Bras-David and Corossol river

The connectivity index helps us to assess the watershed quality and distinguish which need an in priority a conservation campaign.

The watershed forest of Bras-David, Lézarde and Corossol Rivers in Guadeloupe and Lorrain and Troisbras rivers in Martinique are testing with the fragmentation indices from the land use maps realized during the CARIBSAT project.

These hyperspectral data maps are acquired from Spot 5 for three years between 2008 and 2011 on all the Lesser Antilles. After computation, the shape files landscape territories of ten meters resolutions are subdivided in seven lands uses classes:

\begin{tabular}{|c|}
\hline Built \\
\hline Agricultural and vegetated zoned \\
\hline Vegetation forestry \\
\hline Non-forest vegetation \\
\hline Mangrove \\
\hline Naked ground \\
\hline Water \\
\hline
\end{tabular}

Figure 3. Land use types of CARIBSAT project

\begin{tabular}{|c|c|c|}
\hline Islands & Watershed & Landscape characterizes \\
\hline \multirow{7}{*}{ Guadeloupe } & Bras-David & Protected forest area \\
\cline { 2 - 3 } & Lézarde & $\begin{array}{c}\text { Upstream in protected } \\
\text { forest area } \\
\text { Downstream in } \\
\text { anthropogenic area }\end{array}$ \\
\cline { 2 - 3 } & Corossol & Protected forest area \\
\hline
\end{tabular}

Figure 4. Study area specificities

For this study we use the Vegetation forestry, degraded forest and the mangrove in a same renamed file for forest areas to evaluate the forest fragmentation. [8]

This choice was made because we want test the corridor function of forest ecosystems hence this union file preserves the principle of the forest continuum.3. Results

\subsection{IIC “Connector Fraction” Result Synthesis}

The "IIC" fraction shows the most efficient habitat for promoting the landscape connectivity. The result orders the greatest biodiversity supplier in species dispersion.

The result of the computation of the IIC index returns a fragmentation map (Figure 5, 6, 8, 10, 12, 14). On those maps the forest patch with more connection capability has a red color. The connection patch value has a very close to the rest of the forest because we are in a protect forest area which creates a large uniform forest area in all watersheds. It could be identified as a connector but this large patch is a reserve of biodiversity and doesn't suffer from fragmentation, unlike in the riverbed of the watershed and upland next to or surrounded by non-forest land use.

The IIC "connector fraction" shows that all isolated patches mostly next to river and at the top of the watershed slope (riparian forest or upland forest) are great connectors between upland forest and non-forest area. It could be explained by their proximity to the non-forest area like agricultural, no-data and water land use classes (figure 7, 9, 11, 13). Thus, they become obligatorily the only bridges within the fragmented forest.

By the way, they have a corridor function in the watershed. Riparian forest seems to be a key to maintain the continuity and biodiversity flow in damaged area. 


\subsubsection{Bras-David Watershed}

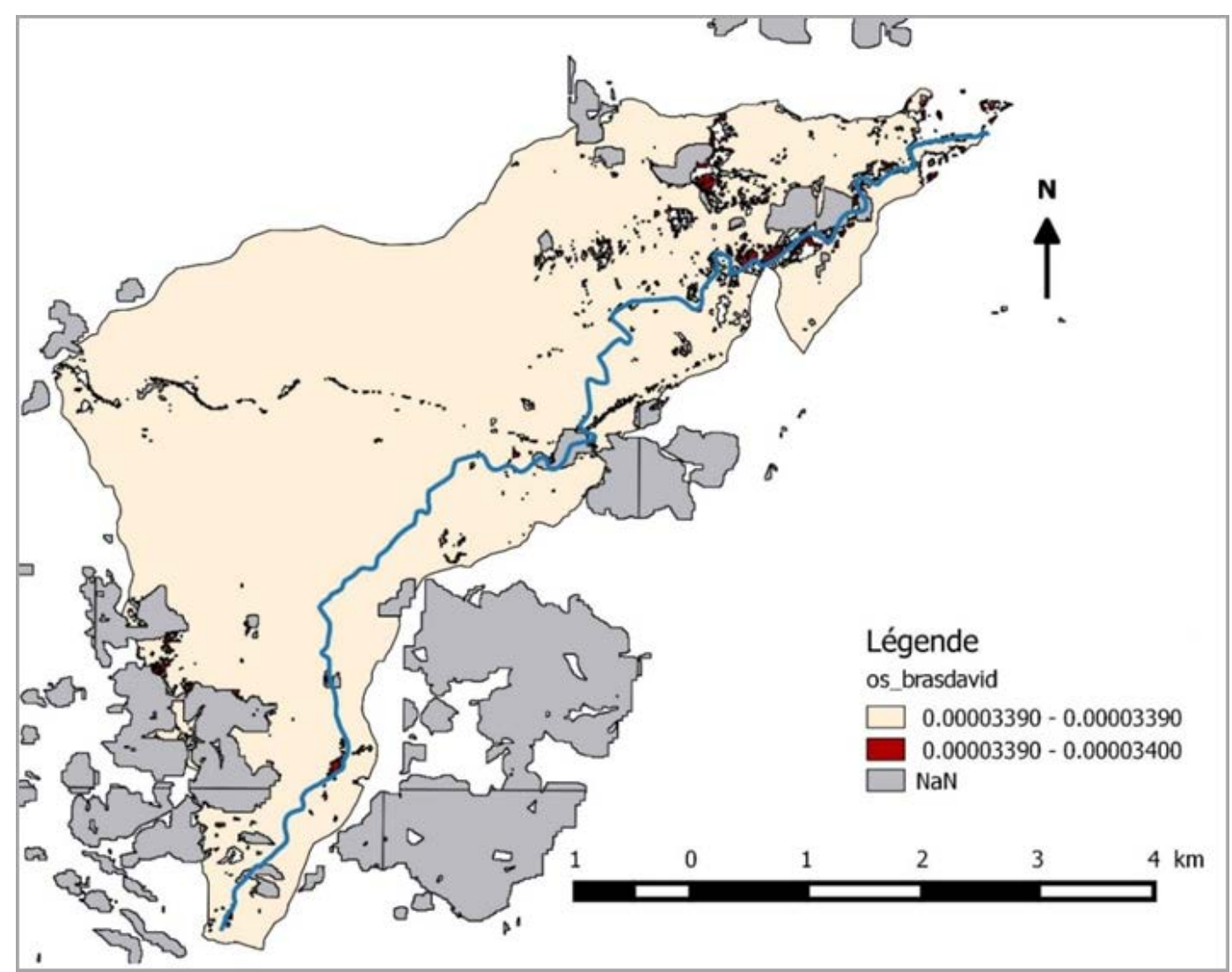

Figure 5. IIC "connector" for the Bras-David watershed: a general view of the watershed in gray the no data value create by a cloud cover, in red forest patch with connector function.

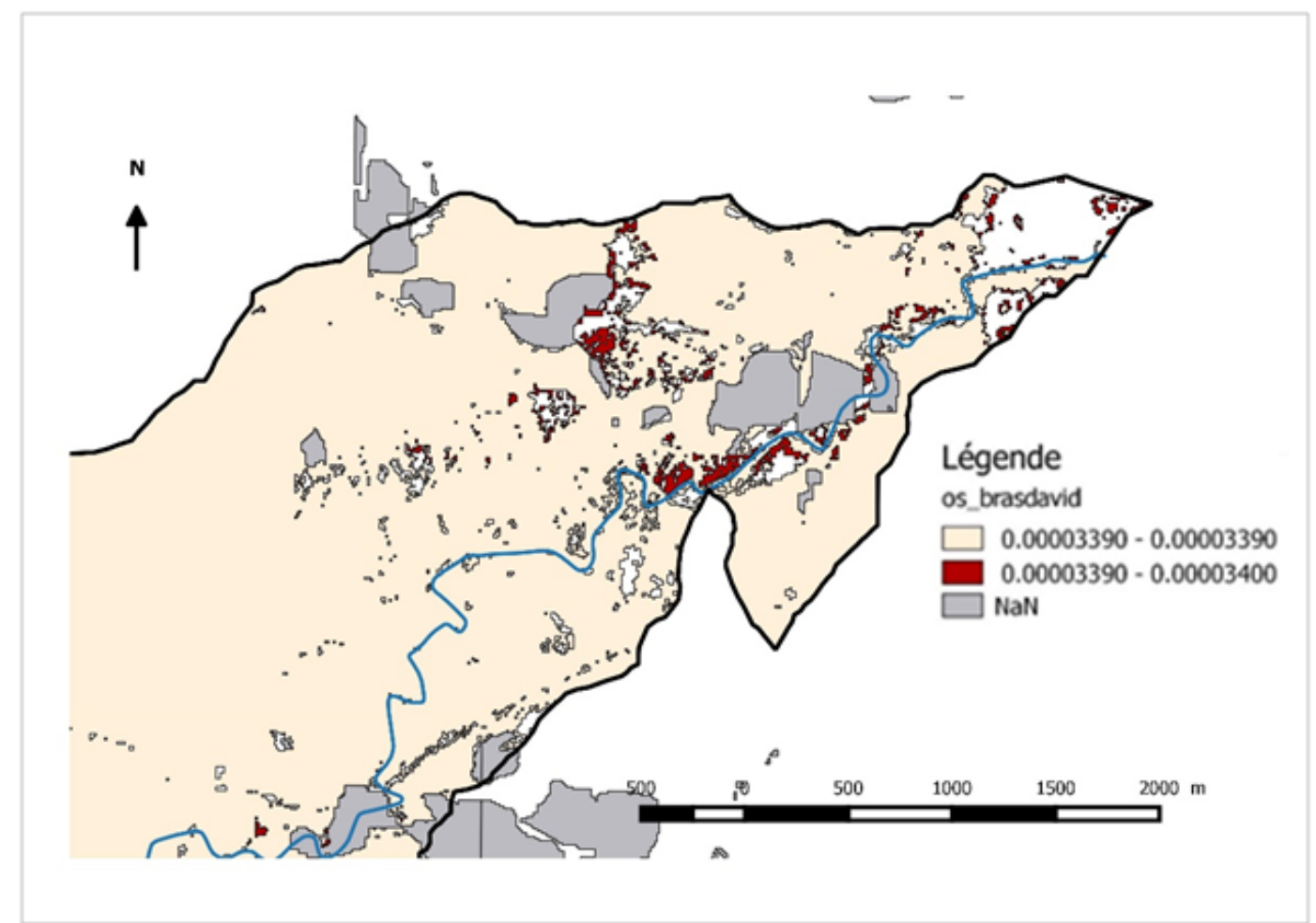

Figure 6. Up watershed fragmentation of Bras-David River: most habitat patches are next to the river except those create by the proximity of the cloud cover 


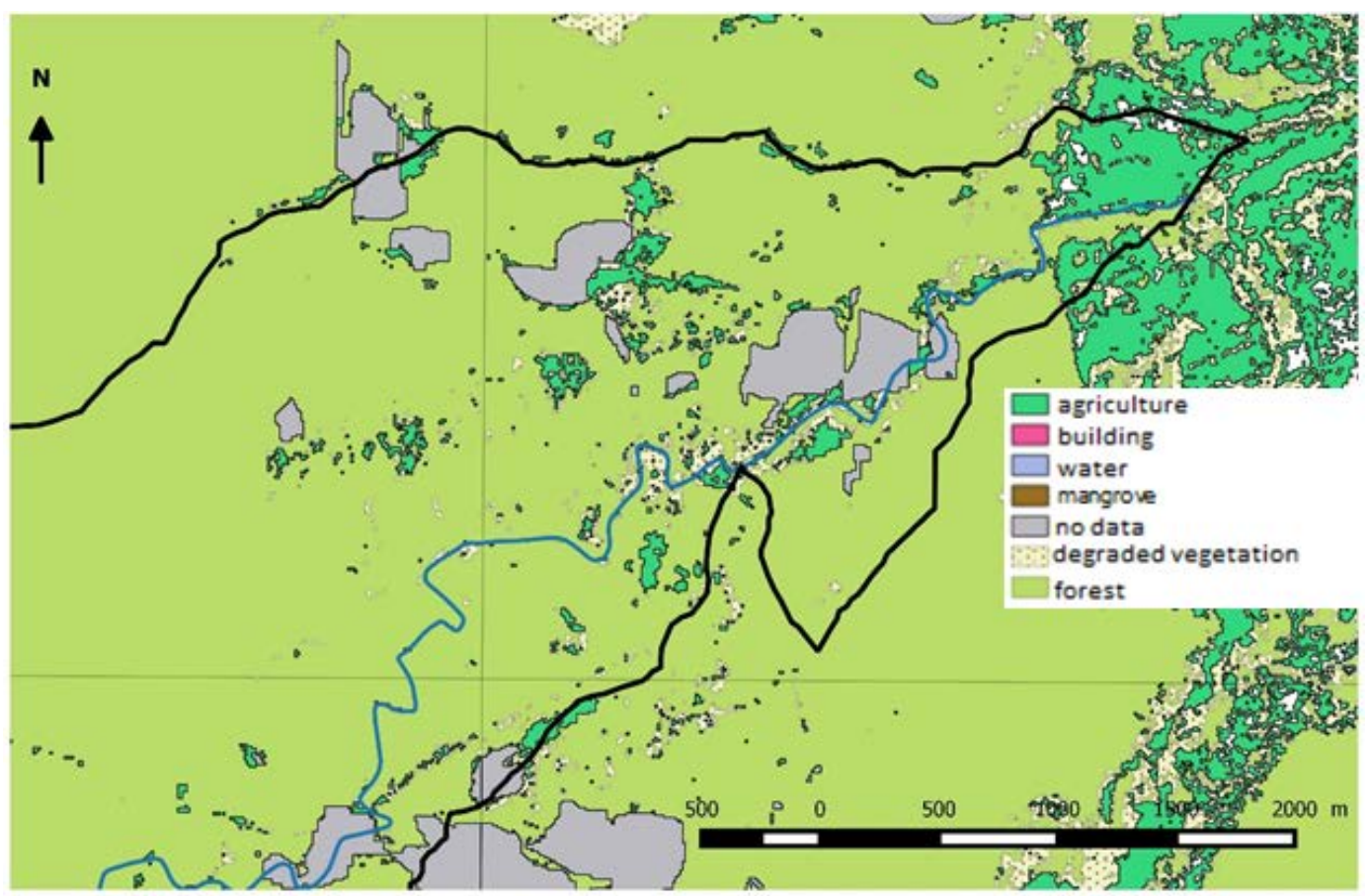

Figure 7. Up watershed land use of Bras-David River: most connector habitat patches are degraded forest next to the channel river, of agricultural fields. It is interesting to observe agriculture land use in the protected forest area maybe they are a wrong interpretation of a very low vegetation (grass) cause by landslides or the river flow.

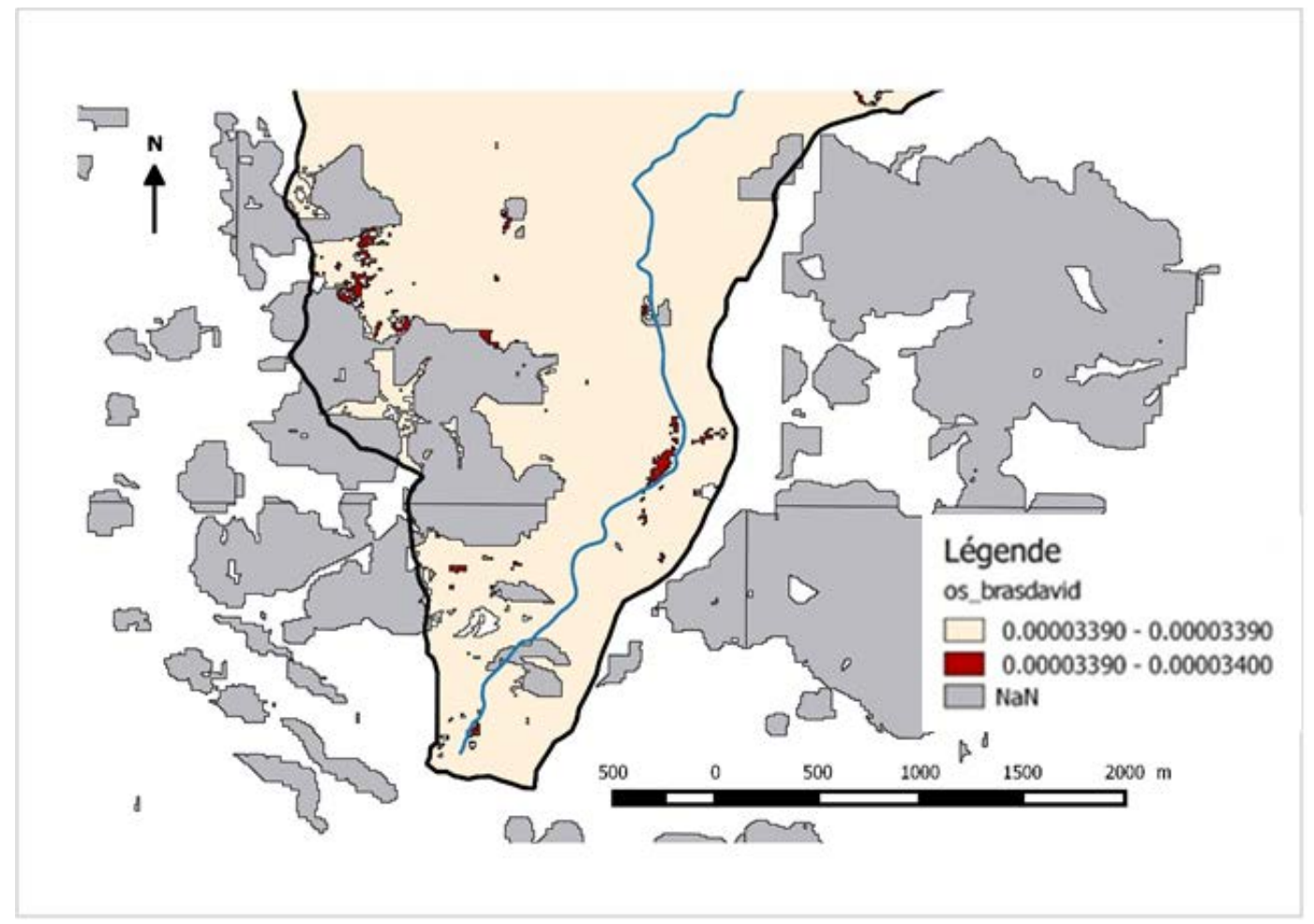

Figure 8. Down watershed fragmentation of Bras-David river: fragmented forest patches are a relay in forest areas. 


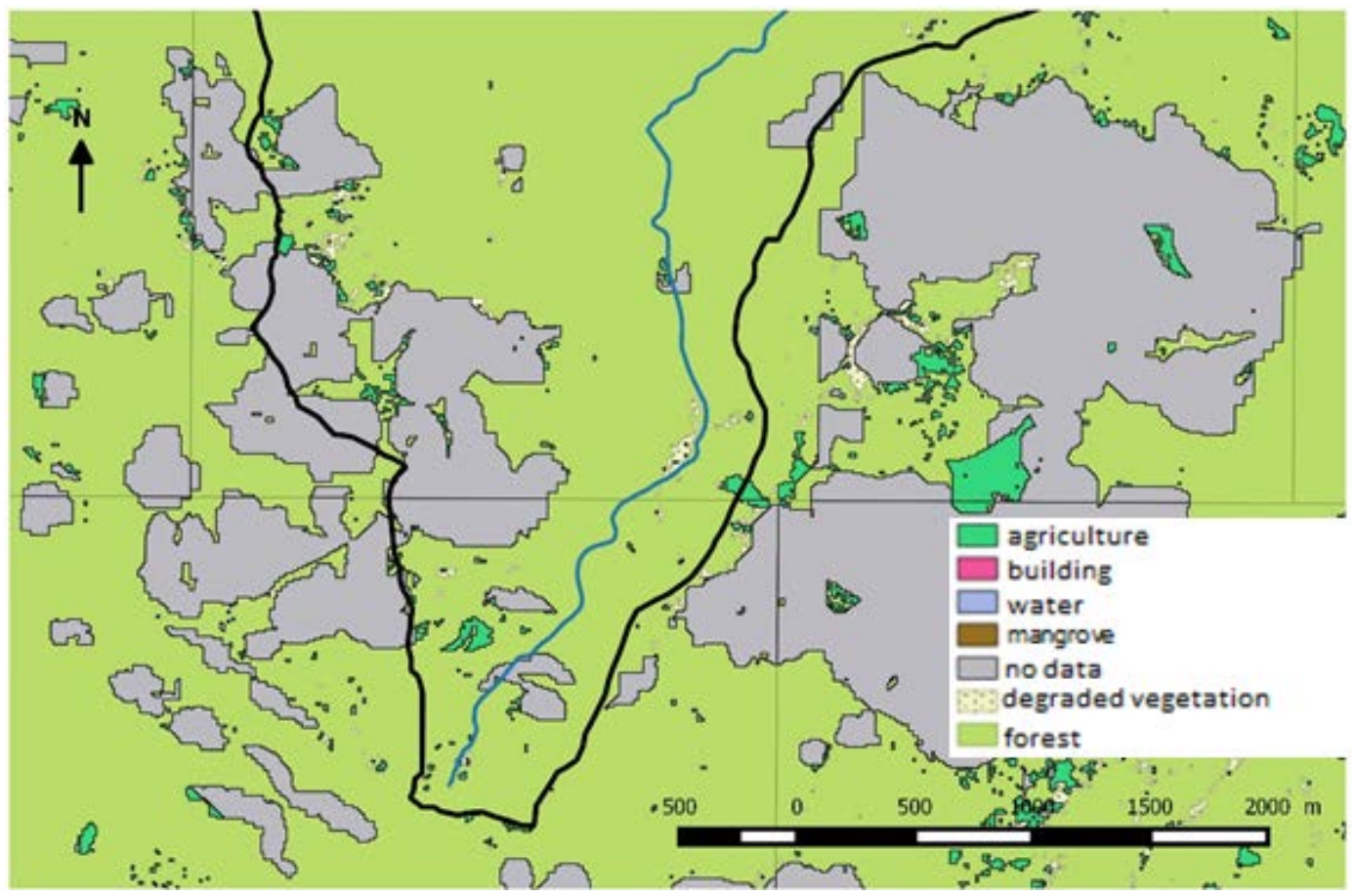

Figure 9. Down watershed land use of Bras-David river

\subsubsection{Corossol Watershed}

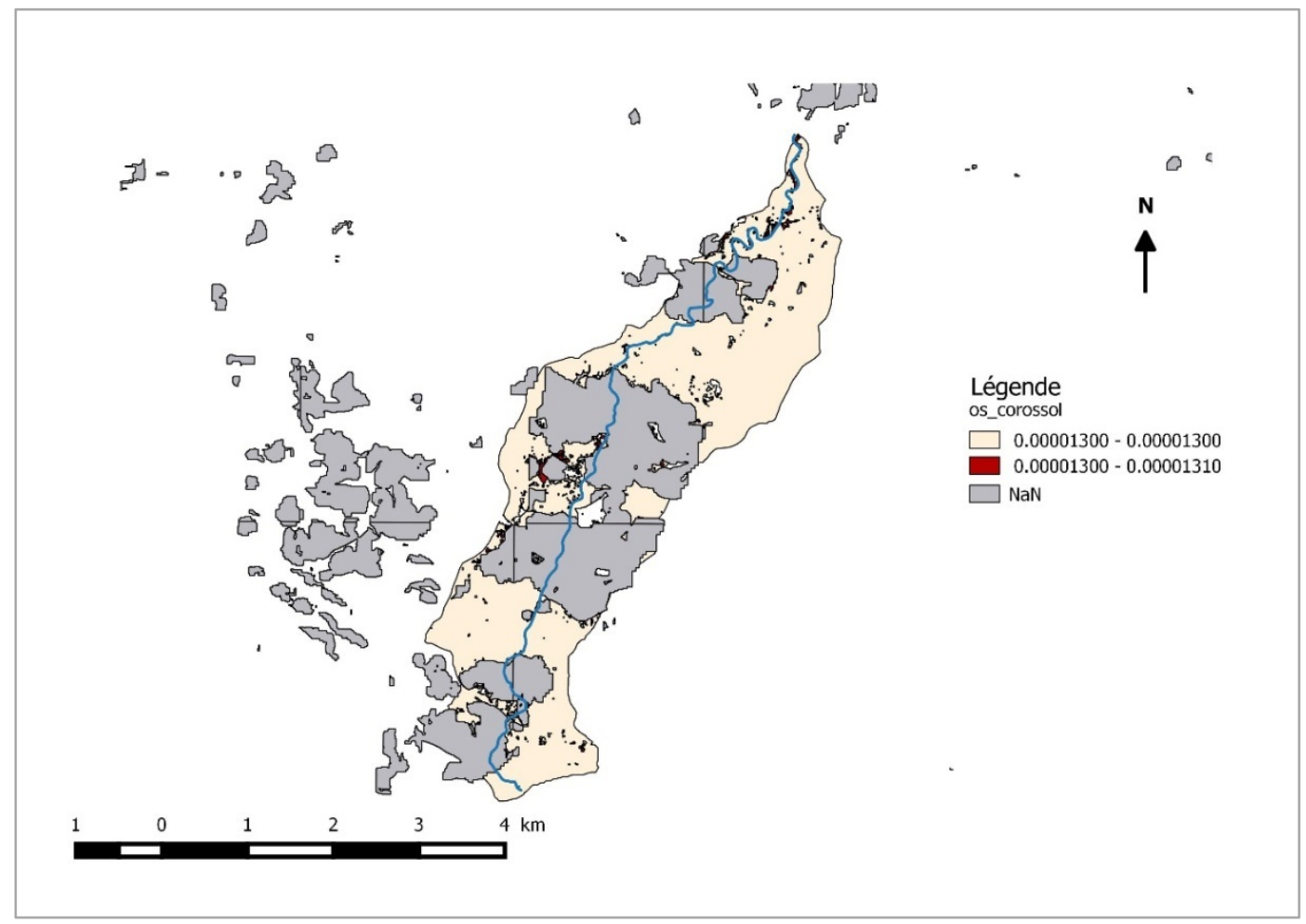

Figure 10. IIC "connector" for the Corossol river watershed: as Bras-David's river, the results of Corossol river showed a more important connector function for the forest patch next to the river. 


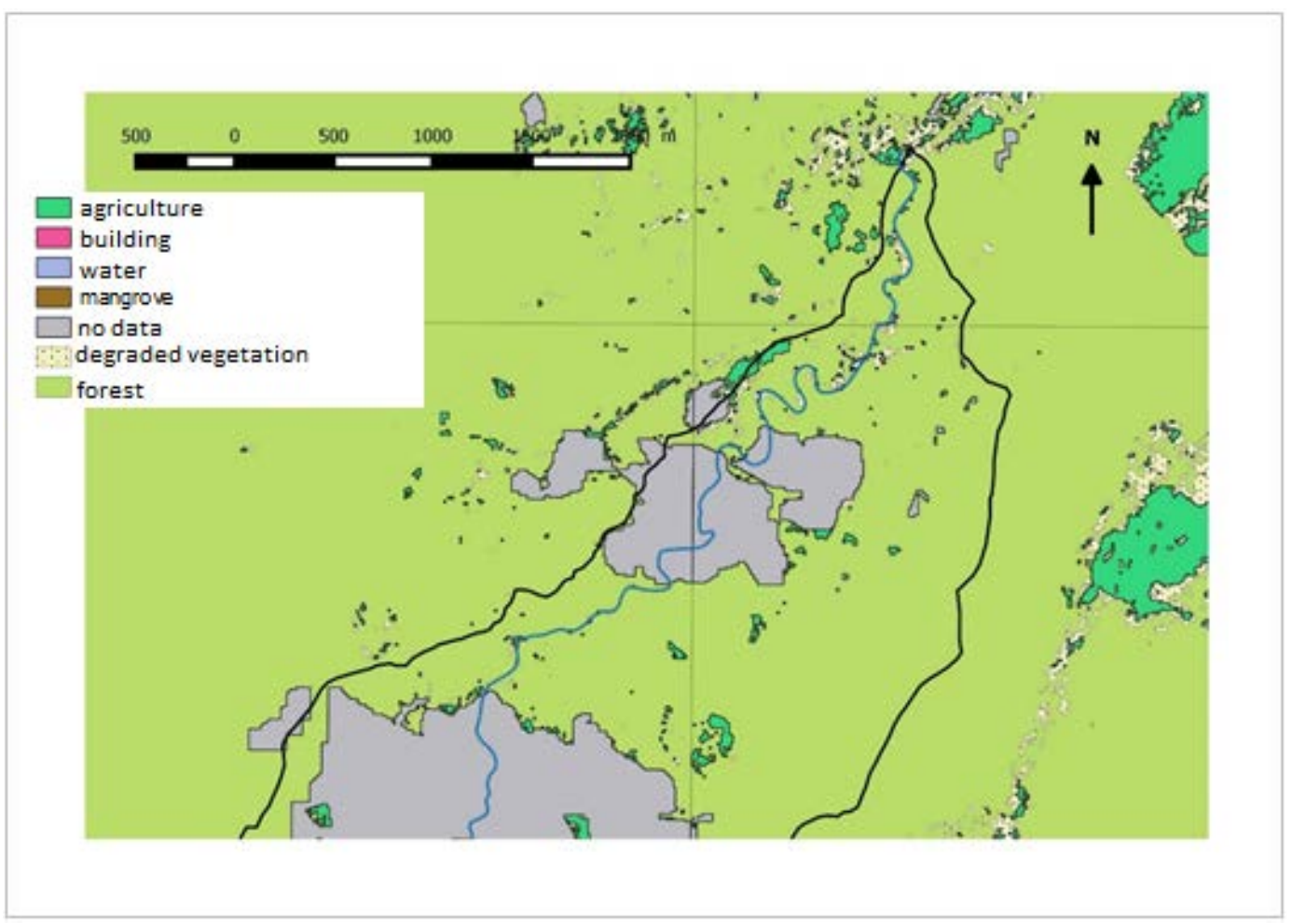

Figure 11. Up watershed land use of Corossol river

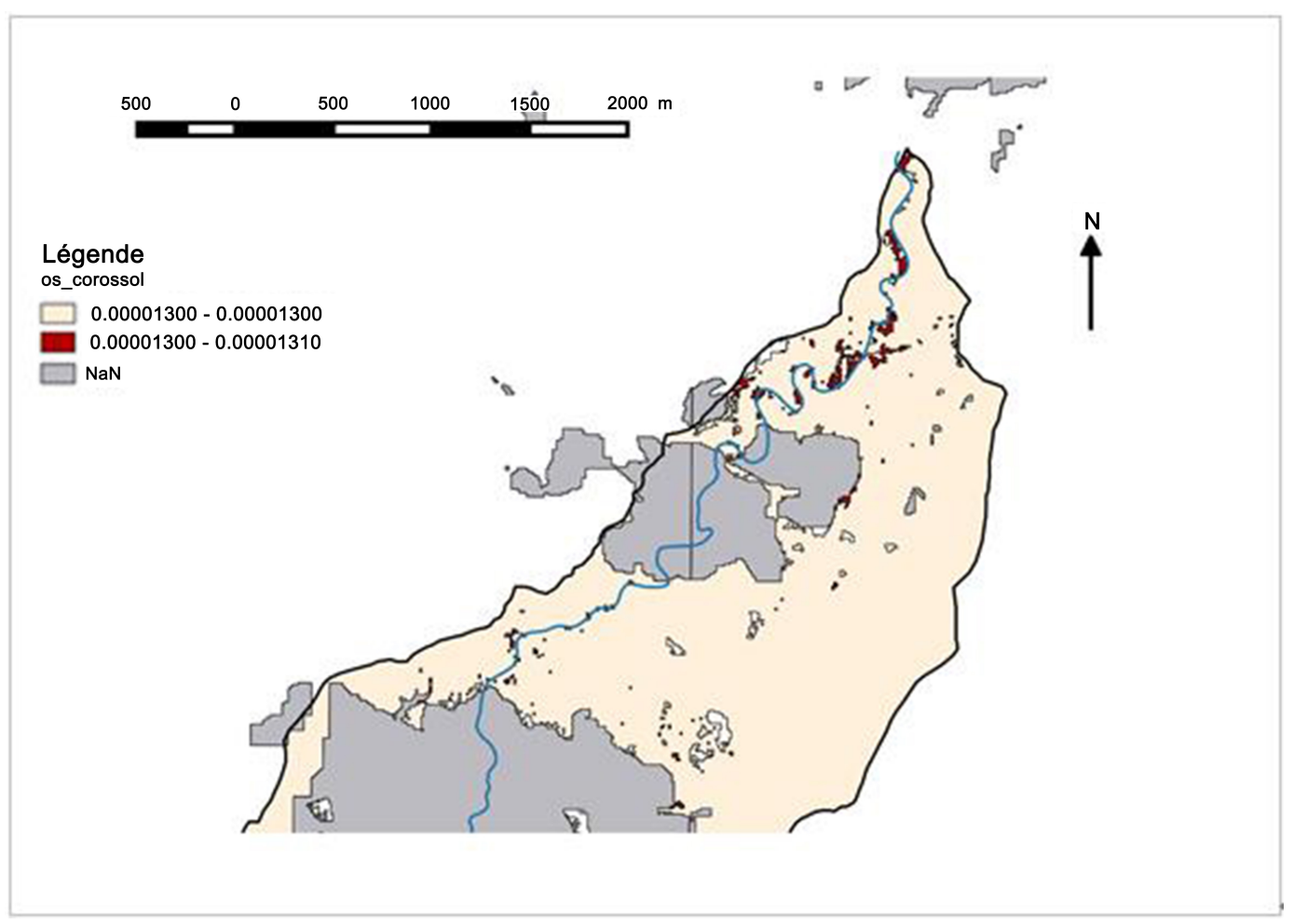

Figure 12. Up watershed fragmentation of Corossol river 


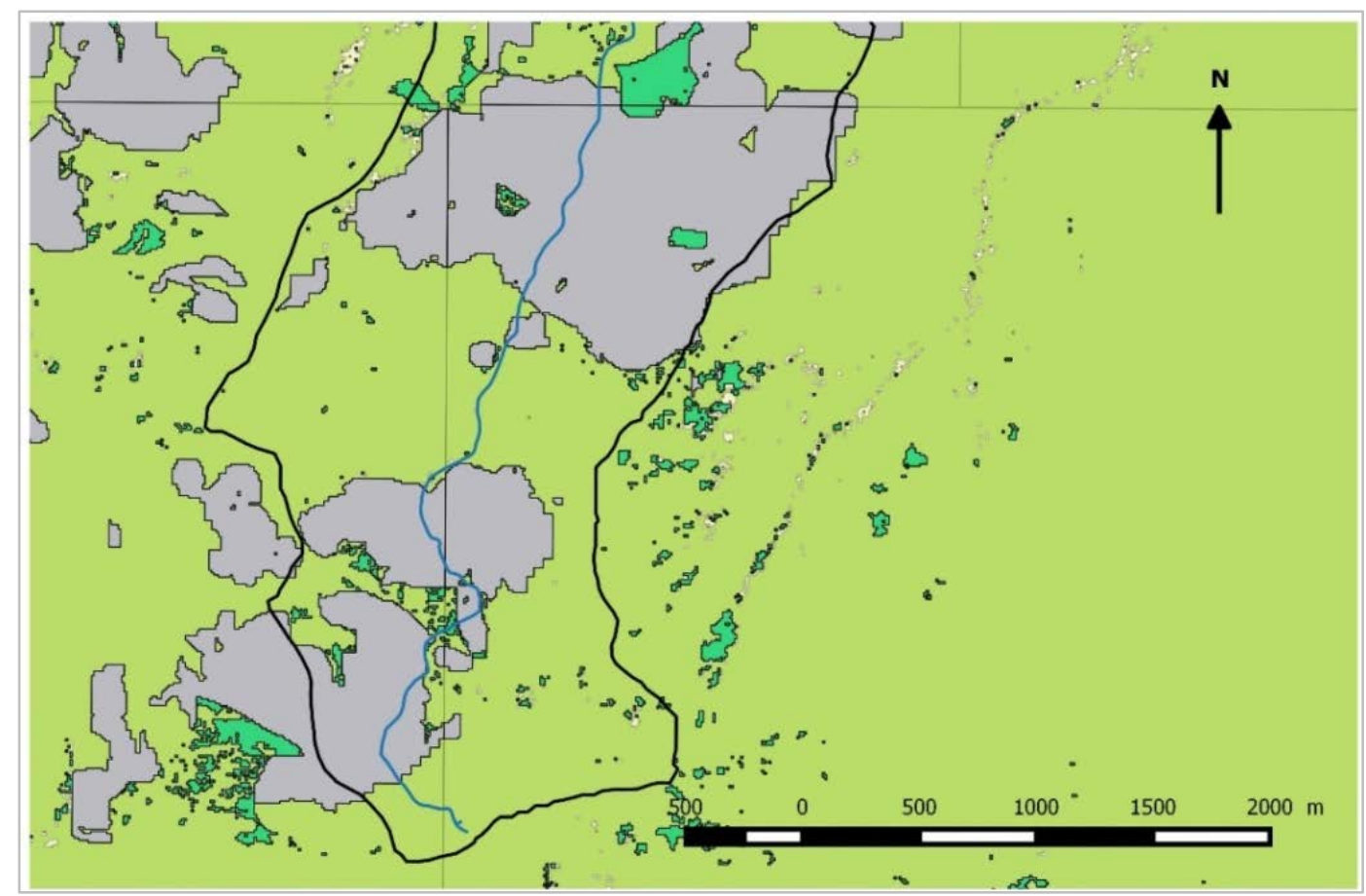

Figure 13. Down watershed of land occupation of Corossol river

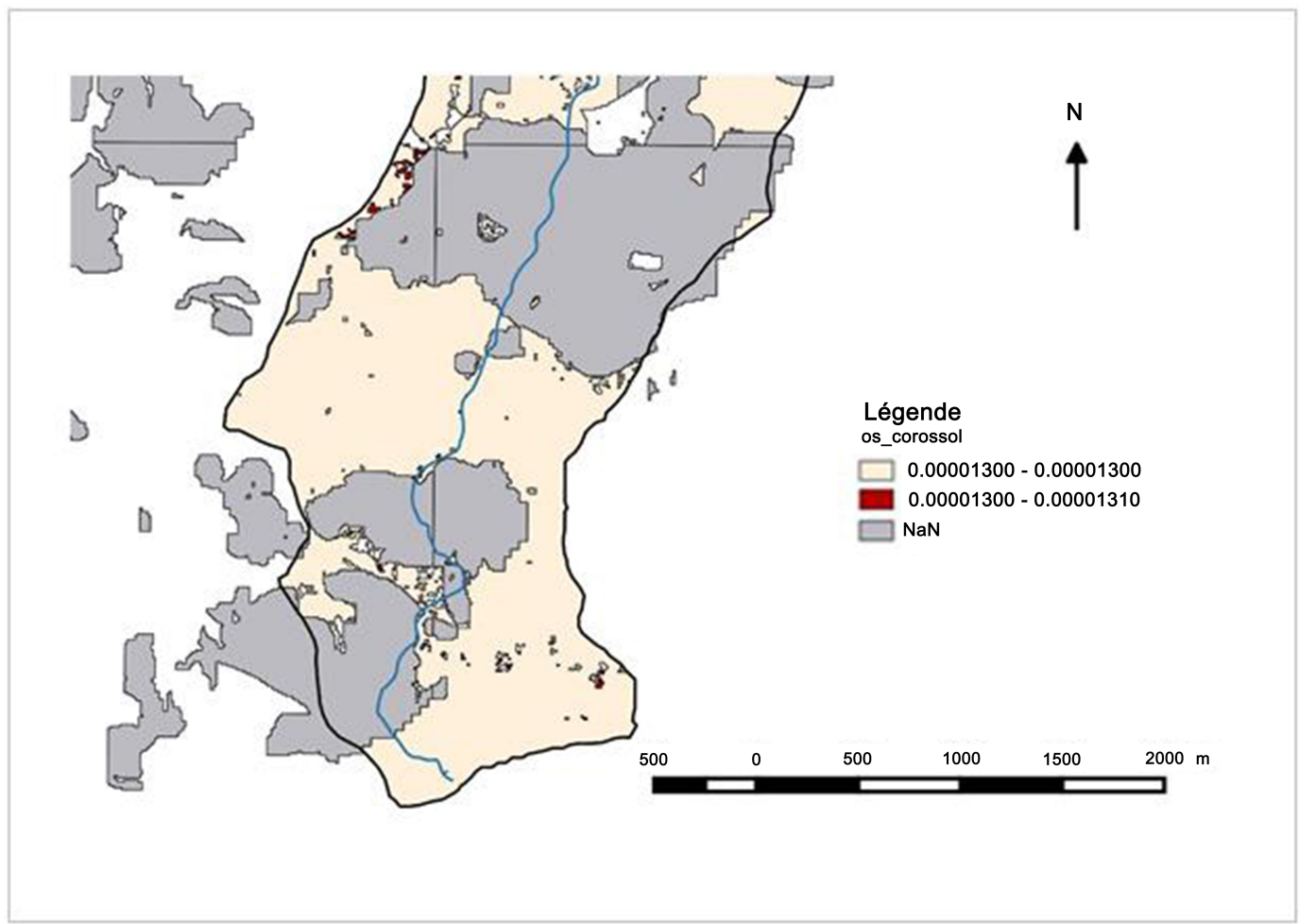

Figure 14. Down watershed fragmentation of Corossol river

Fragmentation appears to be more pronounced at the edges of rivers and on the ridges of watersheds. There are many islands of degraded vegetation in forest environments.

The comparison of land use and fragmentation indexes reveals that islands of degraded vegetation serve as a connector near non-forest areas (classified as agricultural, artifacts due to cloud cover or river channels).

Forest patches wherever they are in the catchment area serve as "bridges" between large forestry complexes. The peculiarity of riparian forest is that this separation on patch is due to the reworking of the forest by the river. Fragmentation appears to be characteristic of riparian forest, even if these 
islands maintain biodiversity.

\section{Discussion \& Conclusions}

The fragmentation index is very useful in the forest management.

Conefor software is helpful to creating the "map of critical areas for connectivity.” [6]

Testing the node importance, reveals that riparian forest is central to maintain biodiversity dispersion and this original use of the fragmentation indices allowed to identify the biological corridor function of riparian forest.

However, other patches of forest at the interfluves of the catchment area (artefact results during remote sensing) also obtain a high value of the connector. This theoretically proves that it is not the riparian forests as such that is a corridor of biodiversity, but any isolated forest ecosystem. The difference between riparian forest and other forest patches is that the degradation of riparian forest is the result most often by the hydrolysis of rivers and of paroxysmal events such as floods. $[9,10,11]$

Riparian forests are at the same time ecosystems that are frequently fragmented because of their interface between the land and the river, but also the solutions to fight the break between large forest reservoir complexes of animal and plant species.

Riparian vegetation like small other forest patches are great connectors between upland forest and non-forest area. They have a corridor function.

Riparian vegetation patch is a key to maintain continuity in damaged area. They are privileged ecotones to develop public management politics.

\section{Acknowledgements}

We are grateful for the assistance of Mr. Marc Morell of the research and development institute of Martinique for the land use data.

We thank the CTM (territorial collectivity of Martinique) for having financed this research work forming part of a thesis on the riparian forest of the Lesser Antilles.

\section{REFERENCES}

[1] Jaeger JAG. Landscape division, splitting index, and effective mesh size: new measures of landscape fragmentation. Landsc Ecol. 2000; 15 (2):115 - 30.

[2] Rey F, Dutoit T, Côte F, Lescourret F. L’ingénierie écologique au service de l'aménagement du territoire. Sci Eaux Territ. 30 août 2016; Numéro 16 (1) : 2-3.

[3] Garnier E, Navas ML. Diversité fonctionnelle des plantes : traits des organismes, structure des communautés, propriétés des écosystèmes. De Boeck; 2013. 354 p.

[4] Bergès L, Roche $\mathrm{P}$, Avon C. Corridors écologiques et conservation de la biodiversité, intérêts et limites pour la mise en place de la Trame verte et bleue. 2010 [cité 6 août 2015] Disponible sur:

http://www.set-revue.fr/corridors-ecologiques-et-conservatio n-de-la-biodiversite-interets-et-limites-pour-la-mise-en-placed/texte

[5] Baranyi G, Saura S, Podani J, Jordán F. Contribution of habitat patches to network connectivity: Redundancy and uniqueness of topological indices. Ecol Indic. Sept. 2011;11(5): 1301-10.

[6] Saura S, Torné J. CONEFOR 2.6 User manual. 2012.

[7] Pascual-Hortal L, Saura S. Comparison and development of new graph-based landscape connectivity indices: towards the priorization of habitat patches and corridors for conservation. Landsc Ecol. 2006; 21 (7):959 - 67.

[8] Cheula A. Cartographie d'occupation des sols des îles des Petites Antilles. IRD, UMR ESPACE-DEV 2012p.73. (CARIBSAT).

[9] Naiman RJ, Decamps H, McClain ME. Riparia: ecology, conservation, and management of streamside communities [Internet].

Academic Press; 2010 [cité 10 août 2015]. Disponible sur : https://books.google.com/books?hl=fr\&lr=\&id=n6i_2G2f2 KAC\&oi=fnd\&pg=PR11\&dq=NAIMAN,+R.J.,+D\%C3\%89 CAMPS,+H.,+Mc+CLAIN,+M.E.,+Riparia+:+ecology,+cons ervation,+and+management + of + streamside + communities, $+\mathrm{E}$ lsevier,+2005\&ots=PhN38JGjwf\&sig=C3DG7ypxkDJZHp_ wOAywLSA3Vco

[10] Piégay H, Pautou G, Ruffinoni C. Les forêts riveraines des cours d'eau : écologie, fonctions et gestion. Institut pour le développement forestier. 2003.

[11] Moore RD, Richardson JS. Natural disturbance and forest management in riparian zones: comparison of effects at reach, catchment, and landscape scales. Freshw. Sci. 2012; 31 (1):239 - 47. 